\title{
Parentesco e Organização Social na Amazônia: um rápido esboço
}

Marcio Ferreira da Silva

Universidade de São Paulo. Brasil

Durante o período de consolidação das matrizes teóricas clássicas da Antropologia, os estudos de parentesco foram guiados pela idéia de que este domínio da vida social correspondia ao núcleo das assim chamadas sociedades primitivas. Tratava-se, em suma, de tomar o parentesco como o plano privilegiado de inteligibilidade, descrição, comparabilidade e totalização da organização social desses povos. Até recentemente, os povos da Amazônia estiveram à margem desta reflexão. O presente trabalho pretende retomar, no horizonte das culturas amazônicas, dois temas tradicionais dos estudos de parentesco. Um deles diz respeito ao tipo terminológico mais freqüente na região, sua forma interna, sua variabilidade e seus correlatos ideológicos e institucionais. O outro está diretamente voltado à relação entre os vocabulários de parentesco e os padrões de atitudes definidos pela culturas amazônicas. Cada um desses temas será precedido de uma pequena introdução teórica.

Palavras Chaves: Amazônia, Povos Indígenas, Parentesco, Organização Social

During the period of their formulation, classical theories of kinship took for granted that their subject matter described the essential features of so-called "primitive societies." In short, kinship was assumed to be the starting point for deciphering, describing, comparing, and grasping the overall principles of the social organization of such societies. Until recently, such analyses have sidelined Amazonian peoples. This paper focuses on Amazonian cultures in order to take up once again two traditional topics within classical kinship studies. The first consists of an overview of the terminologies found most frequently in the region, their structure, variation and ideological and institutional correlates. The second concerns the relation between kinship vocabulary and patterns of attitudes. Each one of these topics is prefaced with a short theoretical introduction.

Keywords: Amazonia, Indigenous Peoples, Kinship, Social Organization

Das contribuições pioneiras de Maine (1861), Morgan (1870) e Durkheim (1897) às de Rivers (1913), Lowie (1928), Radcliffe-Brown (1950) e tantos outros, os estudos de parentesco foram, de um modo geral, guiados pela idéia de que este domínio da vida social correspondia ao núcleo das assim chamadas sociedades primitivas. Tratava-se, em suma, de tomar o parentesco como o plano privilegiado de inteligibilidade, descrição, comparabilidade e totalização da organização social desses povos. Durante o período de consolidação das matrizes teóricas clássicas da Antropologia, de meados do século XIX a meados do século XX, exemplos de sistemas de parentesco de diversas regiões do mundo — como aqueles 
encontrados na América do Norte, Ásia, Melanésia, Austrália e Áfricaforam, pouco a pouco, integrados à investigação.

Até recentemente, os povos da Amazônia estiveram à margem desta reflexão, o que, em larga medida, se justificava pela escassez de informações etnográficas mais precisas sobre o parentesco na região. Para se ter uma idéia deste quadro, basta avaliar a participação desses povos nas sínteses clássicas de Morgan (1870), Lowie (1928) e Murdock (1949), nula no primeiro caso e demasiado discreta nos demais. Na introdução a uma coletânea de artigos recentes sobre parentesco amazônico, Viveiros de Castro (1995:7-8) chama a atenção para o que denomina o "desencontro históri$c o$ " entre as trajetórias da teoria antropológica geral e da etnologia sul-americana. Segundo o autor, enquanto o interesse da disciplina pelo tema era muito vivo, havia muito pouco material disponível sobre o parentesco ameríndio. Quando, a partir da década de setenta, as pesquisas etnográficas nas terras baixas da América do Sul conheceram um desenvolvimento sem precedentes, o tema do parentesco "entrava em hibernação teórica".

Se tomarmos como marcos iniciais dos estudos de parentesco na América do Sul tropical as monografias precursoras de Curt Nimuendaju sobre a estrutura social dos Apinayé (1939), Xerente (1942) e Timbiras Orientais (1946), assim como as análises pioneiras de Lévi-Strauss sobre o uso dos termos de parentesco entre os índios brasileiros (1943) e sobre a vida familiar e social dos Nambikuara (1948), nos defrontamos com uma reflexão de mais de seis décadas. Seu desenvolvimento, contudo, não obedeceu a um padrão uniforme. Até a virada dos anos setenta, seu exercício foi de certa forma tímido. As três últimas décadas, no entanto, assistiram a uma mudança radical neste fluxo, com o avanço quantitativo e qualitativo de pesquisas etnográficas na região. Tais investigações foram também beneficiadas pelas sucessivas revisões críticas das duas teorias de parentesco de ambição universal, a dos Grupos de Descendência, desenvolvida pelo estrutural-funcionalismo britânico (Radcliffe-Brown, Evans-Pritchard, Meyer Fortes e outros), e a da Aliança de Casamento, formulada pelo estruturalismo lévi-straussiano, assim como pelos desdobramentos recentes dessa última (Dumont, Héritier, Viveiros de Castro, etc.). Tal conjunção favorável propiciou um maior fôlego dos estudos de parentesco na região, com a definição de uma problemática própria, que este artigo pretende explorar.

Se isso é verdade, este texto não tem, contudo, a intenção de traçar uma história dos estudos de parentesco amazônico desde seus primórdios aos dias atuais, o que exigiria a consideração de um sem número de refe- 
rências, estilos e tendências, tarefa ingrata para as proporções de um artigo. Os interessados em uma visão abrangente do campo poderão recorrer ao utilíssimo roteiro de Laraia (1987), que acompanha cuidadosamente os desenvolvimentos iniciais desses estudos no Brasil, às generalizações etnográficas pioneiras de Rivière (1984), Hornborg (1988) e Henley (1996), e ao balanço teórico de Viveiros de Castro (2001:87-180).

$\mathrm{O}$ presente trabalho pretende trilhar um outro caminho. Baseado em minha própria experiência etnográfica entre os Waimiri-Atroari, povo caribe da Amazônia (Silva 1993a, 1993b e 1995), o texto retoma, no horizonte das culturas da região, dois temas tradicionais dos estudos de parentesco, cuja consideração, a meu ver, favorece uma via de acesso à paisagem em questão. Um deles diz respeito à estrutura dos vocabulários de parentesco amazônicos, subjacente à notável heterogeneidade lingüística e cultural da região, ao exame de algumas variantes locais e à consideração de possíveis correlatos ideológicos e institucionais. O outro está diretamente voltado à relação entre os vocabulários de parentesco e os sistemas de atitudes nas culturas amazônicas. O campo de pesquisa tradicionalmente denominado estudos de parentesco articula duas ordens de realidade inextrincavelmente imbricadas: sistemas terminológicos, que consistem em vocabulários e padrões de atitudes, que correspondem a condutas determinadas em função das relações sociais que os indivíduos estabelecem entre si. A consideração de cada um desses temas requer uma pequena introdução teórica. No fim, o leitor encontrará um pequeno glossário dos termos técnicos empregados ao longo do artigo.

\section{Os sistemas de parentesco amazônicos}

O Nordeste da América do Sul corresponde a um vasto território habitado por algumas dezenas de sociedades nativas que guardam entre si um notável grau de homogeneidade sociológica. Esta Região, também conhecida na literatura etnográfica como Guiana, é geograficamente circunscrita pelos Rios Amazonas, Negro, Orinoco e pelo Oceano Atlântico. Politicamente dividida entre a Venezuela, Guiana, Suriname, Guiana Francesa e Brasil, abriga povos de diferentes famílias lingüísticas (carib, tupi, aruak, yanomamî, makú e outras famílias menores). Observa-se aí a recorrência de uma paisagem social marcada pela atomização política, pela filiação indiferenciada, pela uxorilocalidade, pela ausência de unidades segmentares de caráter permanente, como clãs, linhagens, classes de idade 
etc., e de fórmulas globais de integração social, como sistemas de metades, chefias (chiefdoms) etc.. Espacialmente dispersas, essas populações tendem a se distribuir em núcleos residenciais cujo total de habitantes comumente não ultrapassa dois dígitos e por uma forte tendência a endogamia dos grupos locais (Rivière 1984:2-5).

Nesta paisagem, observa-se ainda a generalização de vocabulários de parentesco que evocam imediatamente figuras sobre as quais a Antropologia tem se debruçado desde seus primórdios. Para se ter uma idéia dos desafios formulados por tais fenômenos, basta dizer que já figuravam da agenda de um dos principais precursores da disciplina, Morgan (1870), para quem as diferenças entre vocabulários como os da Índia do Sul (dravidianos), tipologicamente idênticos aos amazônicos, e os de tradição européia correspondiam a sua célebre distinção entre sistemas de parentesco classificatórios e descritivos. Para o autor, enquanto esses últimos se caracterizavam pela presença de termos complexos derivados de termos simples, por um caráter mais analítico em relação aos fatos genealógicos e pela incorporação da distinção entre parentes lineares e colaterais, os primeiros, ao contrário, eram marcados por um léxico constituído unicamente de termos simples, por englobarem muitos tipos de parentes em poucas categorias sintéticas e por confundirem parentes lineares e colaterais.

Algumas décadas depois da publicação da macro-tipologia de Morgan, a reflexão sobre os vocabulários dravidianos, também conhecidos como sistemas de duas seções, foi retomada por Rivers (1913), a partir de materiais etnográficos da Índia (Gond) e da Melanésia (Fiji, Novas Hébridas e Guadalcanal). Segundo o autor, tais sistemas correspondiam a correlatos lingüísticos do costume de casamento de primos cruzados. Nos anos seguintes, uma nova macro-tipologia, elaborada por Lowie (1928), vem substituir a de Morgan. No lugar da oposição entre sistemas classificatórios e descritivos, o autor propôs um esquema que define quatro grandes tipos de vocabulários de parentesco, com base no método de classificação dos parentes da primeira geração ascendente: geracionais ( $\mathrm{FB}=\mathrm{F}=\mathrm{MB})$, fusão bifurcada $([\mathrm{FB}=\mathrm{F}] \neq \mathrm{MB})$, colateralidade bifurcada $(\mathrm{FB} \neq \mathrm{F} \neq \mathrm{MB})$ e linear $([\mathrm{FB}=\mathrm{MB}] \neq \mathrm{F}){ }^{1}{ }^{1} \mathrm{De}$ acordo com a nova proposta, os

1 Emprego a seguinte notação para indicar as posições de parentesco: $\mathrm{F}=$ pai, $\mathrm{M}=$ mãe, $\mathrm{B}=$ irmão, $\mathrm{Z}=$ irmã, $\mathrm{S}=$ filho, $\mathrm{D}=$ filha, $\mathrm{C}=$ filhos, sem distinção de sexo, $\mathrm{H}=$ marido, $\mathrm{W}=$ esposa, $\mathrm{G}=$ irmãos de ambos os sexos. Os símbolos $\mathrm{G}_{+2}, \mathrm{G}_{+1}, \mathrm{G}_{0}, \mathrm{G}_{-1}, \mathrm{G}_{-2}$, indicam os níveis geracionais, respectivamente o dos avós, o dos pais, o dos irmãos, o dos filhos e o dos netos. Nos diagramas, triângulos representam homens, círculos mulheres, uma linha horizontal unindo por baixo dois símbolos significa relação de casamento, por cima, relação entre irmãos. Uma linha vertical significa filiação. 
vocabulários dravidianos, "afetados pelo casamento de primos cruzados" (Lowie [s.d.] 1968:49), foram interpretados como de fusão bifurcada.

Nos anos quarenta, Radcliffe-Brown ([1940] 1952) propôs uma revisão geral das hipóteses sobre os vocabulários de parentesco, à luz dos desenvolvimentos da teoria da descendência. Nesse novo quadro, os sistemas de duas seções foram tomados como produtos de um mecanismo de dupla descendência, e a regra de casamento de primos cruzados como um efeito trivial da exogamia dos grupos. Em contraponto a essa hipótese, LéviStrauss (1949) interpretou a regra de casamento de primos como manifestação, no plano do parentesco, do Princípio da Reciprocidade (Mauss 1923-4). Seguindo essa nova trilha, Louis Dumont $(1953,1957)$ demonstrou que os vocabulários dravidianos de fato expressavam tal regra, que lhes servia de pedra angular. Essas terminologias gravitavam ainda em torno de uma dicotomia nativa, consangüinidade e afinidade, atributos equistatutários, ambos transmitidos de geração em geração, ao contrário do que acontece nos sistemas de tradição européia. Enquanto em um sistema europeu, por exemplo, o cunhado do pai de ego é o seu tio materno e a cunhada da mãe, a sua tia paterna, nos sistemas em questão (indianos e amazônicos), cunhado do pai e cunhada da mãe são respectivamente identificados às figuras de sogro e sogra e assim por diante.

$\mathrm{Na}$ década seguinte, a reflexão sobre os sistemas dravidianos ganhou um novo impulso com as pesquisas de Yalman (1962) sobre o casamento de primos cruzados bilaterais e a organização das parentelas endogâmicas cingalesas. A despeito da controvérsia entre Dumont e Yalman, que interpretaram diferentemente o mesmo fenômeno, ora como função do imperativo da troca e "expressão do matrimônio" (Dumont 1953), ora como derivado dos "direitos e obrigações entre irmãos e irmãs" (Yalman 1967:358), as análises de ambos foram decisivas para demonstrar que os sistemas de duas seções (e a regra de casamento de primos bilaterais) podiam operar independentemente da presença dos grupos de descencência unilinear.

Os modelos de Dumont e Yalman desempenharam um papel fundamental não apenas nas paisagens asiáticas em que foram forjados, mas também no cenário amazônico, região em que os sistemas de parentesco igualmente expressavam uma regra de casamento de primos cruzados bilateral operando em estruturas sociais predominantemente marcadas pela filiação indiferenciada e pela inexistência de unidades exogâmicas permanentes. Devemos especialmente a americanistas como Rivière (1969) e Overing 
(1975) a iniciativa do diálogo promissor entre os materiais etnográficos dessas duas regiões do mundo, geograficamente tão distantes.

Paralelamente ao desenvolvimento da reflexão sobre o sistema dravidiano, as teorias do parentesco foram submetidas, especialmente a partir da segunda metade do século XX, a uma longa bateria de críticas e revisões conceituais, como as de Schneider (1972), Needham (1971) e Kuper (1988), que, entre outras coisas, levaram ao abandono da premissa de ouro dos estudos clássicos, já evocada no início deste artigo: a de que o parentesco era o núcleo central das assim chamadas "sociedades primitivas".

Graças a essas revisões, a reflexão, no lugar de tomar aprioristicamente o parentesco como o plano de inteligibilidade e totalização desses povos, tratava agora de interpretar o seu sentido e determinar o seu lugar na organização social apenas a posteriori. Neste novo quadro, os estudos passaram a levar a sério as concepções nativas sobre as quais esses sistemas repousavam, assim como as representações e instituições sociais por eles afetados. A consideração dos sistemas amazônicos, em toda sua riqueza etnográfica, revelou também que o parentesco na Região correspondia a uma ordem sintética, infletida por fluxos econômicos, esquemas sóciopolíticos e classificações cosmológicas. Seu estudo, em suma, era inescapável para aqueles interessados nas formas amazônicas de vida social.

A leitura americanista da monumental obra de Trautmann (1981) sobre os sistemas dravidianos indianos estimulou a retomada do exercício comparativo entre os materiais asiáticos e amazônicos iniciado na década anterior. Se, em um primeiro momento, as semelhanças entre as regiões é que chamavam a atenção dos americanistas, a partir de meados dos anos oitenta o desafio passou a ser, como assinalou Viveiros de Castro (1993), o de determinar as diferenças. Isso porque ambas as regiões, além de associarem a grade vocabular a uma norma de casamento bilateral, operando em regimes de filiação indiferenciada, registravam variações terminológicas (inflexões havaianas ou iroquesas) e matrimoniais (preferência pelo casamento patrilateral ou avuncular) muito semelhantes, assim como notáveis homologias no ajuste entre os níveis categorial (semâtico), normativo (jurídico) e empírico (prático) do parentesco.

Segundo Viveiros de Castro (1993), se as semelhanças eram mesmo inegáveis, talvez a principal diferença entre os sistemas asiáticos e os amazônicos estivesse situada no modo como as categorias de consangüinidade e a afinidade se definiam, uma em relação a outra, nessas duas regiões. Especialistas nos sistemas asiáticos como Dumont descreviam-nas como 
categorias equistatutárias ou, em outras palavras, como princípios que se relacionavam de modo notavelmente simétrico. Assim, tanto as relações de consangüinidade quanto as de afinidade de um dado indivíduo transmitiam-se, com a mesma ênfase, de geração em geração, segundo um cálculo circular que se voltava para todas as direções do universo do parentesco. Assim, por exemplo, na geração de ego, os parentes consangüíneos de seus parentes consangüíneos são seus consangüíneos $(\mathrm{C}+\mathrm{C} \rightarrow \mathrm{C})$; os parentes consangüíneos de seus parentes por afinidade são seus afins $(\mathrm{C}+\mathrm{A} \rightarrow \mathrm{A})$; os parentes por afinidade de seus parentes consangüíneos são seus afins $(\mathrm{A}+\mathrm{C} \rightarrow \mathrm{A})$; e parentes por afinidade de seus afins são seus consangüíneos $(\mathrm{A}+\mathrm{A} \rightarrow \mathrm{C})$. Em suma, consangüinidade e a afinidade correspondiam, nos sistemas indianos, a atributos contraditórios, que operavam em um plano puramente categorial, isto é, sem qualquer suporte genealógico.

Enquanto isso, nos sistemas amazônicos, consangüinidade e afinidade não se relacionavam simetricamente, mas de forma hierárquica, correspondendo a atributos contrários. Este fenômeno estaria associado ao fato desses sistemas gravitarem em torno de oposições sócio-cosmológicas típicas das culturas amazônicas, que organizam o espaço social com base nas categorias de interioridade exterioridade, proximidade e distância, identidade e diferença. Nesse quadro, a consangüinidade engloba a afinidade no plano local e é por ela englobada no plano global. A casa, o espaço aldeão, a roça, a vida cotidiana a família, os co-residentes, a parentela e assim por diante (Overing 1984) remetem diretamente ao universo da consangüinidade. Enquanto isso, as relações entre os grupos locais, a vida cerimonial, a floresta, os territórios distantes, a feitiçaria e a inimizade são marcados pelo signo da afinidade. Afinidade que, nos sistemas amazônicos, se submetia a gradações bastante curiosas. Assim, os Trio estudados por Rivière (1969) distingüem o "afim aparentado" do "afim não aparentado", o primeiro, ligado por laços de parentesco anteriores e sociologicamente equivalente a um consangüíneo, o segundo, um forasteiro. Para com seus sogros, por exemplo, o primeiro teria muito menos deveres e muito mais prerrogativas que o outro.

Dessa forma, o parentesco amazônico estaria situado na interseção de coordenadas genealógicas (históricas) e geográficas da vida social, com consequiências diretas para os vocabulários da região. Ao contrário dos sistemas dravidianos indianos, estruturados a partir do que denominamos princípio de circularidade, operando com base em um cálculo puramente categorial, a variante amazônica seria infletida por um princípio de latera- 
lidade (Silva 1995), capaz de distinguir parentes próximos e distantes em diversos graus, tornando assim não trivial a referência genealógica. Esta característica da paisagem amazônica será retomada adiante. Passemos agora à consideração mais de perto dos vocabulários em questão.

Como foi dito acima, os sistemas amazônicos com base na oposição consangüíneos e afins. Tais noções correspondem à versão nativa da distinção entre parentes paralelos e cruzados. Outras oposições, como aquelas que produzem as diferenças geracionais e etárias, concorrem também para a caracterização dos vocabulários da Região (Rivière 1984:42-48), cuja estrutura subjacente é aqui representada por uma grade (Figura 1) em que cada espaço corresponde a uma classe de parentes que se define por oposição a todas as demais. Embora não existam dois sistemas de parentesco idênticos na região, todos repousam sobre um mesmo regime de troca direta (Rivière 1984:43).

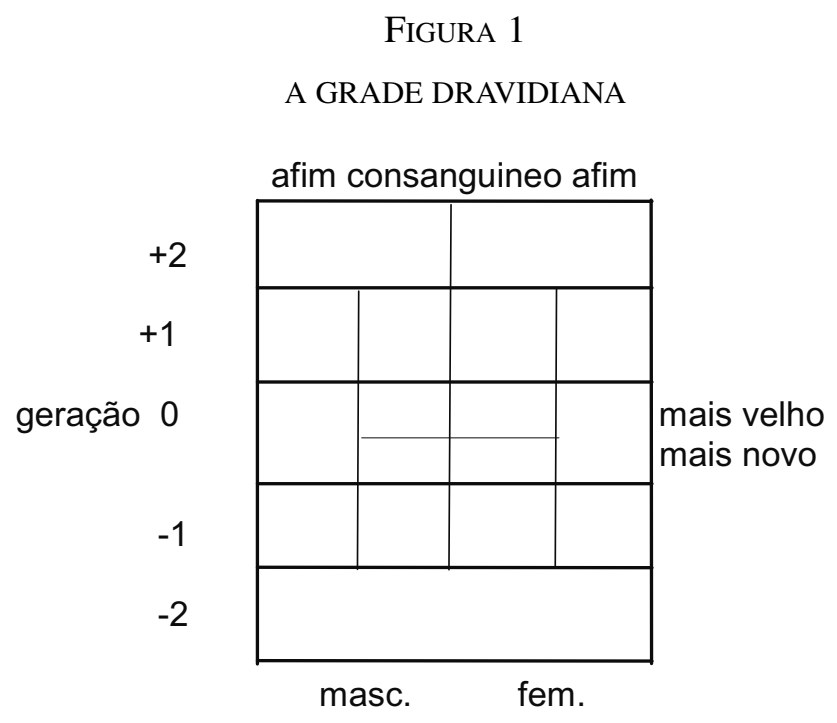

A Figura 2 procura dar uma idéia da variabilidade verificada no interior do paradigma vocabular na Região. Consideremos, para começar, seis exemplos extraídos da etnografia. Tomemos esses casos como variantes de uma mesma estrutura subjacente. Os materiais Panare, Pemon, Piaroa, Trio e Ye'cuana e Waimiri-Atroari foram recolhidos, respectivamente, das etno- 
grafias de Henley 1982, Thomas 1978, Overing 1975, Rivière 1969 e Arvelo-Jimenes 1971 e Silva 1993. Na tabela abaixo (Figura 2), o atributo "típica" não significa a forma mais comum na Região, mas aquela que se manifesta exatamente como prevê o tipo definido acima.

\section{FIGURA 2}

VARIAÇÕES SOBRE O TEMA DRAVIDIANO

\begin{tabular}{|c|c|c|c|c|c|c|}
\hline $\begin{array}{l}\text { Povos: } \\
\text { Parâmetros: }\end{array}$ & Panare & Pemon & Piaroa & Trio & Ye'cuana & $\begin{array}{l}\text { Waimiri - } \\
\text { Atroari }\end{array}$ \\
\hline $\begin{array}{l}\text { parente } \\
\text { cruzado / } \\
\text { afim }\end{array}$ & \begin{tabular}{|l} 
termos \\
específicos \\
para afins \\
apenas na \\
geração de \\
ego. \\
\end{tabular} & $\begin{array}{l}\text { termos } \\
\text { específicos } \\
\text { para "sogra" } \\
\text { e "marido da } \\
\text { irmã". }\end{array}$ & $\begin{array}{l}\text { termos } \\
\text { específicos } \\
\text { para afins } \\
\text { (tecnô- } \\
\text { nimos) }\end{array}$ & $\begin{array}{l}\text { termos } \\
\text { específicos } \\
\text { para afins }\end{array}$ & $\begin{array}{l}\text { termos } \\
\text { específicos } \\
\text { para afins } \\
\text { apenas nas } \\
\text { gerações }+1 \\
\text { e }-1 \text {. }\end{array}$ & típica \\
\hline sexo & típica & típica & típica & típica & típica & típica \\
\hline $\begin{array}{l}\text { idade / } \\
\text { geração }\end{array}$ & $\begin{array}{l}\text { "filhos de } \\
\text { filho" } \\
\text { idênticos a } \\
\text { "irmãos"; } \\
\text { "filhos de } \\
\text { filhas" } \\
\text { idênticos a } \\
\text { "primos } \\
\text { cruzados" }\end{array}$ & típica & \begin{tabular}{|l|} 
"irmãos \\
mais \\
velhos" \\
idênticos à \\
G+3; \\
"irmãos \\
mais novos" \\
idênticos à \\
G-3
\end{tabular} & típica & $\begin{array}{l}\text { afins da } \\
\text { G+1 } \\
\text { identicos à } \\
\text { G+3; afins } \\
\text { da G-1 } \\
\text { identificos à } \\
\text { G-3 }\end{array}$ & típica \\
\hline $\begin{array}{l}\text { consangüi- } \\
\text { nidadel } \\
\text { afinidade }\end{array}$ & $\begin{array}{l}\text { mantém } \\
\text { oposição } \\
\text { C/A nas } \\
\text { G+2 e -2 }\end{array}$ & $\begin{array}{l}\text { neutraliza } \\
\text { oposição } \\
\text { C/A entre } \\
\text { parentes da } \\
\text { G0 de sexo } \\
\text { oposto }\end{array}$ & \begin{tabular}{|l} 
neutraliza \\
oposição \\
C/A entre \\
parentes da \\
G0 de sexo \\
oposto
\end{tabular} & $\begin{array}{l}\text { neutraliza } \\
\text { oposição } \\
\text { entre "filhos } \\
\text { de irmão" e } \\
\text { "de irmã" }\end{array}$ & $\begin{array}{l}\text { neutraliza } \\
\text { oposição } \\
\text { C/A entre } \\
\text { G0 de sexo } \\
\text { oposto }\end{array}$ & típica \\
\hline $\begin{array}{l}\text { graus de } \\
\text { distância } \\
\text { entre } \\
\text { parentes } \\
\text { consan- } \\
\text { güíneos e } \\
\text { afins }\end{array}$ & típica & típica & típica & típica & típica & $\begin{array}{l}\text { estabelece } \\
\text { distinção } \\
\text { entre } \\
\text { parentes } \\
\text { lineares e } \\
\text { colaterais } \\
\text { nas G+1 e - } \\
1 \text {; e entre } \\
\text { afins do } \\
\text { mesmo sexo } \\
\text { na G0 }\end{array}$ \\
\hline
\end{tabular}

O sistema waimiri-atroari, que conhecemos mais de perto, contém alguns termos de parentesco que se referem unicamente a uma posição gene- 
alógica. Outros denotam um número indeterminado de posições. Os termos que correspondem a uma única posição genealógica são os seguintes:

$\begin{array}{ll}\text { yimî } & \mathrm{F} \\ \text { sanî } & \mathrm{M} \\ \text { yin } & \mathrm{H} \\ \text { pîtî } & \mathrm{W} \\ \text { mîrîkî } & \mathrm{S} \\ \text { bikî } & \mathrm{S} \text { } \\ \text { yimekî } & \mathrm{D} \text { ㅇ }\end{array}$

Os termos que correspondem a um número indeterminado de posições genealógicas são:

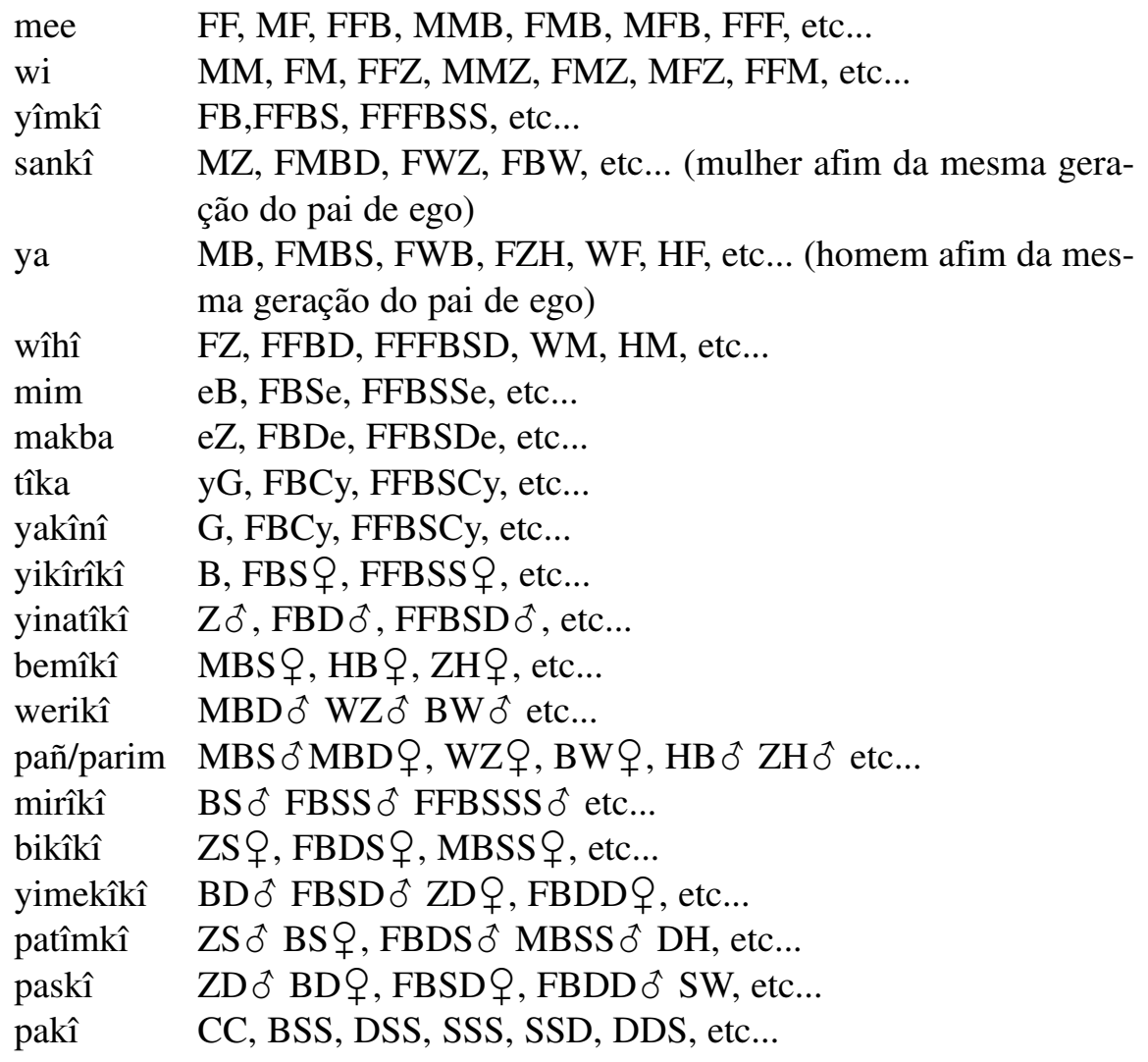


Praticamente, todas as variantes (formas não "típicas") verificadas nos sistemas amazônicos foram igualmente observadas por Trautmann (1981) no cenário indiano. Mas, como veremos a seguir, o sentido de pelo menos uma delas nos remete diretamente à diferença entre as duas paisagens. Refiro-me àquela que define graus de distância entre parentes consangüíneos e afins. Na amostragem acima (Cf. Fig. 2), observamos que apenas os Waimiri-Atroari expressam-na terminologicamente, mas como veremos adiante, outros povos também a incorporaram. Para interpretá-las, a reflexão deve retroceder às paisagens nativas que as produziram. Voltemo-nos a uma delas.

Os Waimiri-Atroari somam uma população de 798 indivíduos (em 1999) que habita um território localizado no extremo norte do Brasil, entre os Estados do Amazonas e Roraima. Este contingente populacional, condensado em aglomerados, ${ }^{2}$ se distribui em grupos locais que são comunidades de 40 pessoas em média, formadas por unidades domésticas, cada uma delas em torno da cozinha de uma mulher casada e da roça de seu marido. Como a maioria dos povos da região, os Waimiri-Atroari concebem o grupo local como uma comunidade econômica e politicamente autônoma, reunida em uma casa, que é designada pelo nome de seu chefe.

Para além das variáveis naturais ou demográficas, a configuração e a dinâmica desses grupos locais não dependem apenas dos laços sociais entre seus membros, mas de suas relações inter-comunitárias, notadamente reiteradas por casamentos virilocais de filhos de chefes de casa e por rituais de iniciação masculina, assim como eventuais disputas por mulheres e por agressões xamanísticas. Enquanto as duas primeiras práticas correspondem a fatores de aproximação das comunidades, as duas últimas evidentemente equivalem a vetores de distanciamento. Essas práticas, em certo sentido, previnem tanto a atomização absoluta dos grupos locais quanto o seu oposto, isto é, a unificação desses grupos em unidades maiores e com maior diferenciação interna.

Os assim chamados Waimiri-Atroari referem-se a si mesmos como "gente" (kiña), termo que pode ocorrer livremente ou em locuções como "meu povo" (a-kiña-riri, literalmente "minha-gente-coletivo"). Esta expressão é sinônima de uma outra, "os cunhados de meus cunhados" ( $a$ -

2 "Aglomerados" são articulações multi-comunitárias não-corporadas e não-segmentares, constituídas pelo adensamento de redes de relações sociais estabelecidas entre parentelas bilaterais, cada um deles associado a um território não nomeado, mas identificado a um curso d'água importante. 
parim-parim), que traduz precisamente a idéia de um universo social cimentado pela afinidade. Os Waimiri-Atroari se dizem "parentes" (yaska) uns dos outros não porque descendem de um ancestral comum, mas porque são fruto de uma cadeia histórica de elos matrimoniais. Em sua acepção máxima, o termo yaska define idealmente o conjunto da população waimiri-atroari; em sua acepção mínima, as pessoas que constituem uma unidade doméstica. Grupos locais geograficamente distantes podem ser eventualmente classificados como "não parentes" (yaska-kapî). As categorias nativas, em suma, mesclam, como já foi dito, a dimensão genealógica da cognação à dimensão geográfica da co-residência.

Viveiros de Castro (1993:166) propôs um esquema que situa as oposições entre cognato e não cognato, consangüíneo e afim, co-residente e não co-residente em níveis analíticos distintos de um mesmo esquema conceitual. Para o autor, o primeiro par estabelece uma "distinção sociológica, de natureza concêntrica e contínua, que contém uma referência genealógica não trivial", o segundo remete a uma "distinção terminológica, de natureza diametral, de conteúdo categorial" e o terceiro a uma "distinção terminológica diametral". Ora, esse esquema prevê graficamente representado na Figura 3 prevê um desdobramento não mencionado pelo autor: se os pares cognato vs. não cognato e co-residente vs. não co-residente representam distinções sociológicas —o primeiro fundado em uma oposição concêntrica (gradual), o segundo, em uma oposição diametral (privativa)—e se ambos se opõem ao par consangüíneo e afim (distinção terminológica, fundada em uma oposição diametral), o esquema conceitual produz também uma quarta possibilidade combinatória, que define uma distinção terminológica concêntrica. Mas teria algum rendimento analítico tal distinção?

O sistema de parentesco waimiri-atroari e o de outros povos da região incorporam exatamente esta possibilidade. Esta distinção, como veremos abaixo, é o que permite estabelecer, no plano dos vocabulários de parentesco, uma diferença radical entre a paisagem amazônica e asiática. Podemos encontrar manifestações do fenômeno não apenas entre os Waimiri-Atroari, mas também entre outros povos da região como, por exemplo, os Waiyana (Lapointe 1970:109-110), Aparaí (Koehn 1975:845), Akawaio (Colson apud. Rivière 1984:47) e Caribes do Rio Barama (Adams 1972:128-33).

Para termos uma clareza maior sobre esse ponto, comecemos por observar mais de perto o material Waimiri-Atroari. Comparemos dois exemplos limites do cálculo classificatório nativo (Figura 4). No primeiro 
FIGURA 3

VARIAÇÕES TERMINOLÓGICAS CONCÊNTRICAS (de proximidade e distância)

\begin{tabular}{|c|c|c|c|c|c|}
\hline $\begin{array}{l}\text { Povos: } \\
\text { Parâmetros: } \\
\text { graus de distância } \\
\text { entre parentes } \\
\text { consangüíneos e } \\
\text { afins }\end{array}$ & $\begin{array}{l}\text { Waiyana } \\
\text { estabelece } \\
\text { distinção } \\
\text { entre } \\
\text { parentes } \\
\text { masculinosli } \\
\text { neares e } \\
\text { colaterais } \\
\text { nas G+1 e } \\
\text { G-1 }\end{array}$ & $\begin{array}{l}\text { A paraí } \\
\text { estabelece } \\
\text { distinção } \\
\text { entre } \\
\text { parentes } \\
\text { lineares e } \\
\text { colaterais na } \\
\text { G+1 }\end{array}$ & \begin{tabular}{|l|} 
Akawaio \\
estabelece \\
distinção \\
entre \\
parentes \\
masculinos \\
lineares e \\
colaterais na \\
G+1
\end{tabular} & $\begin{array}{l}\text { Caribes do } \\
\text { Rio Barama } \\
\text { estabelece } \\
\text { distinção } \\
\text { entre } \\
\text { parentes } \\
\text { lineares e } \\
\text { colaterais } \\
\text { nas G+1 e } \\
\text { G-1 }\end{array}$ & $\begin{array}{l}\text { Waimiri - } \\
\text { Atroari } \\
\text { estabelece } \\
\text { distinção } \\
\text { entre } \\
\text { parentes } \\
\text { lineares e } \\
\text { colaterais } \\
\text { nas G+1 e } \\
\text { G-1; e entre } \\
\text { afins do } \\
\text { mesmo sexo } \\
\text { na G0 }\end{array}$ \\
\hline
\end{tabular}

FigURA 4

LINEARIDADE / COLATERALIDADE

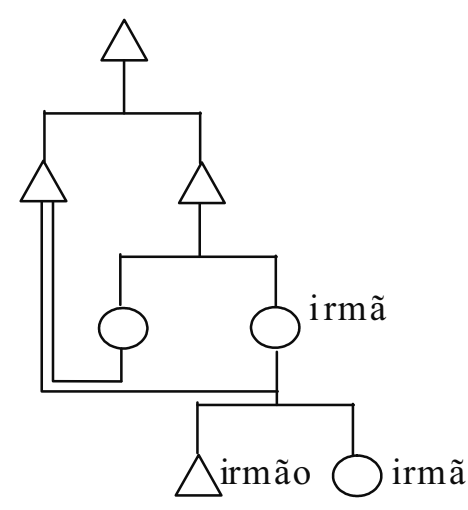


caso, uma mulher (ego) e sua irmã são casadas com um irmão de seu pai (filhos de um mesmo homem). Os filhos de sua irmã são classificados como irmãos classificatórios e não como sobrinhos, como era de se esperar. No segundo caso, uma mulher (ego) e sua irmã são casadas com um primo paralelo de seu pai (filhos de dois irmãos). Neste e em todos os outros casos, os filhos de sua irmã são classificados, como era de se esperar, sobrinhos.

O único traço que diferencia as duas situações focalizadas na Figura 4 é que, no primeiro caso, marido e pai de ego são irmãos reais e, no segundo, classificatórios. A dimensão aqui denominada de lateralidade (ou distância lateral) é, por essa razão, irredutível no caso amazônico, ao contrário do que ocorre na paisagem asiática, tal como Dumont e Trautmann demonstraram. Nos sistemas indianos, sua eventual ocorrência corresponde a uma manifestação meramente lexical, já que, a rigor, em todos os casos estudados, F/FB etc..., M/MZ etc... constituem classes semânticas. Tal irredutibilidade, na paisagem amazônica, tem como resultado, a emergência de um curioso ternarismo $(\mathrm{F} \neq \mathrm{FB} \neq \mathrm{MB}$, etc. $)$ em sistemas de ... duas seções, onde tradicionalmente deveríamos identificar, a cada geração, apenas duas classes de parentes ([F=FB $] \neq \mathrm{MB}$, etc.). $\mathrm{O}$ que estamos observando aqui é a projeção, no plano do parentesco por consangüinidade, de graus de distância lateral (ou lateralidade). Este traço constitui uma das formas de expressão da oposição sócio-cosmológica de base que, no plano do parentesco, remete, como já observamos, tanto à ordem temporal da genealogia quanto à ordem espacial das relações de vizinhança. No universo dos parentes por afinidade, podemos da mesma forma observar este princípio em operação: a língua waimiri-atroari distingue dois tipos de "primos-cruzados / cunhados (reais ou virtuais)", os próximos (pañ) e os distantes (parim), respectivamente co-residentes e não co-residentes para a distinção. Aqui, convém registrar, a informação genealógica é irrelevante. Apenas a dimensão geográfica é que conta. Passemos assim ao próximo ponto do artigo.

Passemos assim ao próximo ponto do artigo: a notável generalização do paradigma terminológico norte amazônico, tão bem explorada por autores como Rivière se defronta, no entanto, com uma afirmação do autor, pelo menos à primeira vista, desconcertante: a virtual ausência na região de regularidades no plano das atitudes (Rivière 1984:67). Antes de nos debruçarmos sobre o novo ponto, devemos tecer algumas considerações mais gerais sobre o problema. 


\section{Terminologias e Atitudes na Amazônia}

A relação entre vocabulário de parentesco e sistema de atitudes corresponde a um tema tão tradicional na disciplina antropológica, quanto aquele sobre o sentido social dos sistemas de duas seções. Uma das primeiras polêmicas travadas, ainda no século XIX, envolvendo Morgan e McLennan, disputava exatamente a questão. Enquanto o primeiro tomava os vocabulários de parentesco como vias legítimas de acesso às instituições sociais e às condutas dos indivíduos nos diferentes estágios de evolução da humanidade, o segundo alegava que os vocabulários de parentesco não passavam de simples fórmulas de etiqueta, desprovidas de qualquer importância sociológica.

Esta questão foi retomada várias vezes na primeira metade do século $\mathrm{XX}$, enquanto a disciplina assistia a seu período de consolidação. Assim, por exemplo, Kroeber (1909) acreditava que os vocabulários não apresentavam qualquer sentido sociológico diretamente relevante. Rivers (1913), como já observamos, afirmava, ao contrário, que os vocabulários de parentesco correspondiam a correlatos lingüísticos de instituições sociais como o casamento. Para Malinowski (1930), tais vocabulários não eram mais que rótulos de relações sociais, cujo estudo parecia ter sido contaminado por uma pseudo-álgebra, não dando a eles (e a ela) qualquer atenção maior. Já Radcliffe-Brown ([1940] 1952) defendia que os vocabulários eram sempre um "reflexo fiel das relações jurídicas" entre os indivíduos, constituindo assim um meio importante para o estabelecimento e reconhecimento dessas relações. Esses exemplos são suficientes para que se possa aferir o interesse e a temperatura deste prolongado debate, com implicações teóricas e metodológicas importantes.

Em meados do século XX, Lévi-Strauss (1945) formulou um método de análise dos sistemas de atitudes, que se recusava a focalizar isoladamente cada relação social, mas procurava observá-las no interior de um sistema de oposições. Embora em sua obra maior sobre o parentesco (Lévi-Strauss 1949), o autor tenha priorizado as estruturas de aliança, os vocabulários não deixaram de ser considerados com atenção em muitos momentos. Além disso, prestou "um tributo aos resultados importantes obtidos e aos projetos fascinantes desenvolvidos por estudiosos que buscam a formulação de regras onde a coerência interna da nomenclatura do parentesco possa ser rigorosamente demonstrada" (Lévi-Strauss [1965] 1969:126). O autor, é verdade, não esconde sua veia irônica diante de alguns bizarros 
exageros da análise formal, como aquela "interessante tentativa de Davis e Warner", em que o sentido do termo 'marido' corresponde à fórmula $C^{2 a} / 2 d /{ }^{\circ} S U^{l a} 8 / E g o$ (Lévi-Strauss 1945: nt. 17). Por outro lado, devemos concordar com Héritier que as análises formais de Lounsbury 1964, "criticáveis que possam ser, permanecem entre as mais estimulantes e esclarecedoras que têm sido escritas sobre os sistemas de parentesco crow e omaha" (Héritier 1989:28). O mesmo poderia ser dito da análise formal de Scheffler (1971) sobre os sistemas iroqueses e dravidianos, retomada por Trautmann (1981), em sua síntese dos sistemas indianos.

Isto posto, convém resumir as noções que interessam mais de perto aos propósitos deste artigo. Em primeiro lugar, tendo como ponto de partida a idéia de que terminologias e atitudes devem ser apreendidas como fenômenos de ordens distintas mas correlacionados, o próximo passo será perguntar que vínculos exatamente podem ser estabelecidos entre os sistemas terminológicos e atitudinais? Para tanto, poderíamos ensaiar hipóteses que, em certo sentido, oscilariam entre versões fraca e forte da relação entre as duas ordens. As hipóteses centradas na versão fraca se contentariam em admitir que os vocabulários e as atitudes podem ser descritos com base nos mesmos pressupostos metodológicos: os da análise estrutural. Já as hipóteses centradas na versão forte reivindicariam, para além das homologias metodológicas, a possibilidade de apontar relações mais profundas entre os dois fenômenos. Este último exercício, em resumo, consistiria em tomar as esferas do parentesco (vocabulário e atitudes) como códigos relativamente autônomos, mas que repousam, pelo menos parcialmente, nos mesmos princípios culturais subjacentes e, em seguida, tentar relacioná-los por um conjunto de transformações. Não se pretende com isso insistir em ver uma correspondência termo a termo entre vocabulários e atitudes mas, como Lévi-Strauss sugeriu, uma integração dinâmica entre as duas ordens de fenômenos.

Ora, o Norte Amazônico se presta admiravelmente ao exercício que acabamos de propor. A coexistência, explorada no início desde artigo, de uma notável recorrência do padrão terminológico, associada à virtual ausência de qualquer regularidade atitudinal, criaria embaraços aparentemente intransponíveis para a defesa de hipóteses que se aproximassem da versão forte da relação entre as duas esferas.

Para se ter uma idéia do grau de variabilidade dos padrões de atitudes na região, voltemos às etnografias dos povos selecionados na Figura 2 acima, e como procedeu Rivière, consideremos abaixo (Figura 5) apenas aquelas que envolvem apenas a geração de ego $(\mathrm{G} 0)$. Retomemos ainda o 
mesmo sistema notacional empregado por Rivière, que define atitudes convencionais que vão de uma maior ou menor intimidade ('++' ou '+' , respectivamente) a uma maior ou menor distância social ('--' ou '-' , respectivamente). A sua notação introduz uma certa gradação no esquema binário empregado por Lévi-Strauss ([1945] 1975:63), em que "o sinal '+' representa as relações livres e familiares [e] o sinal '-' as relações acentuadas pela hostilidade, antagonismo ou reserva ". À primeira vista, diante da Figura 5, deveríamos nos resignar com a ausência de regularidades nos sistema de atitudes da Região.

\section{FIGURA 5}

PADRÕES ATITUdinAIS NO NORTE AMAZÔNICO

(para ego masculino)

\begin{tabular}{|l|c|c|c|c|}
\hline $\begin{array}{c}\text { parentes } \\
\text { povos }\end{array}$ & irmão & irmã & $\begin{array}{c}\text { primo } \\
\text { cruzado }\end{array}$ & $\begin{array}{c}\text { prima } \\
\text { cruzada }\end{array}$ \\
\hline Panare & + & - & ++ & -- \\
\hline Pemon & ++ & + & - & -- \\
\hline Piaroa & ++ & - & -- & + \\
\hline Trio & + & - & -- & ++ \\
\hline Ye'cuana & - & -- & ++ & + \\
\hline $\begin{array}{l}\text { Waimiri- } \\
\text { Atroari }\end{array}$ & ++ & - & + & -- \\
\hline
\end{tabular}

Mas tais regularidades talvez possam ser buscadas em outro plano. Antes de dar início à reflexão comparativa, observemos mais de perto o sistema waimiri-atroari. A aproximação do material etnográfico permitirá conferir conteúdo etnográfico concreto à notação algébrica.

Irmãos do mesmo sexo tendem a ter relações cotidianas freqüentes, íntimas e muitas vezes jocosas (joking), ao contrário do que acontece entre irmãos de sexo oposto. Ainda que o grau de cooperação e de solidariedade entre irmão e irmã seja especialmente alto, raramente, na vida cotidiana, estes parentes ficam a sós ou desempenham juntos alguma atividade. A 
regra de uxorilocalidade é um fator que contribui decisivamente para que irmãs vivam perto umas das outras na idade adulta, em um mesmo grupo local. A prática da poliginia sororal, no mesmo sentido, permite que dividam um mesmo grupo doméstico. Analogamente, entre os homens, a preferência pelo casamento com a irmã da esposa do irmão constitui um fator que propicia destinos matrimoniais (e residenciais) idênticos para um grupo de irmãos. Em resumo, germanos do mesmo sexo fazem o possível para permanecerem juntos ao longo da vida. Mas é preciso morar perto das irmãs, dizem os homens Waimiri-Atroari, e é isso o que parece importar a partir de uma certa idade. Depois de casados, irmãos de sexo oposto tendem, ou, pelo menos se esforçam, a voltar a ser co-residentes, com vistas aos futuros casamentos de seus filhos.

Mas é preciso morar perto das irmãs, dizem os Waimiri-Atroari, e é isso o que parece importar aos homens a partir de uma certa idade. Depois de casados, irmãos de sexo oposto tendem, ou, pelo menos se esforçam, a voltar a ser co-residentes, com vistas aos futuros casamentos de seus filhos. Com os primos-cruzados e irmãos classificatórios (primos paralelos), a situação é, em certo sentido, análoga. Afins de mesma geração e mesmo sexo são, desde criança, companheiros em atividades de cooperação econômica e, posteriormente, parceiros políticos. Entre os primos-cruzados de mesmo sexo, cunhados virtuais ou reais, as relações podem ser de bastante proximidade, mas nunca são jocosas. Enquanto isso, as relações entre afins (reais ou virtuais) de sexo oposto são marcados por um certo constrangimento público, sentimento definido pelos Waimiri-Atroari como "vergonha" (tipkiya) mesmo quando há intimidade sexual. Passemos agora à consideração dos demais exemplos etnográficos.

A comparação dos casos pemon e ye'cuana revelaria, por exemplo, que todos os valores e graus ( ' ++ ' ' + ' ' '-' '--' ) podem ser invertidos na matriz e que, se tomássemos tais casos como os dois extremos de uma série, qualquer combinação intermediária seria igualmente válida. Um reexame dos arranjos atitudinais expressos nesta figura poderia, no entanto, sugerir que a ausência de limitações combinatórias possa corresponder a um fenômeno apenas aparente. Para seguirmos esta pista, devemos admitir, logo de início, que as Figuras 1 e 6 não descrevem fenômenos propriamente do mesmo tipo. Quando afirmamos a recorrência de um padrão vocabular, para além das diferenças lexicais que as terminologias mantêm umas com as outras, não estamos obviamente nos referindo à sua dimensão concreta, mas a seus princípios semânticos subjacentes, invariantes e em 
pequeno número, que o organizam. Em outras palavras, a recorrência terminológica revelada na Figura 1 remete a parâmetros que só podem ser apreendidos pela análise estrutural.

No entanto, quando afirmamos a ausência de um padrão de atitudes na Região, o que estamos fazendo não é mais que uma primeira generalização indutiva a partir dos dados fornecidos pelas etnografias. Estamos ainda no plano de suas manifestações concretas e não no de seus princípios estruturantes. E quais seriam eles? Provavelmente, aqueles mesmos que subjazem às terminologias. Seria preciso, em suma, encontrar evidências que nos convencessem de que padrões de atitudes, como os verificados acima, embora aparentemente díspares, pudessem ser igualmente descritos como variações sobre um mesmo tema. Evidentemente, uma exploração exaustiva deste caminho escaparia aos limites deste artigo, uma vez que requereria a consideração em detalhe de um sem número de variáveis (vocabulares e atitudinais), que a etnografia da região já nos oferece. Poderíamos, no entanto, nos contentar com algo bem menos ambicioso, que permitisse, pelo menos, indicar os rumos a serem explorados para uma possível solução do problema. Isto posto, devemos nos perguntar em que aspecto da etnografia poderíamos apoiar as premissas de nossa hipótese de trabalho ? Ora, é próprio Rivière quem fornece a pista mais atraente: " $[u] m$ traço invariante da organização social da região é que o conjunto de categorias sociais denominadas terminologias de parentesco é articulado por um princípio de troca direta prescritiva " (Rivière 1984:43).

$\mathrm{O}$ "princípio de troca direta prescritiva" remete a uma das formas elementares de reciprocidade definidas por Lévi-Strauss (1949) já evocada na seção anterior, a saber, a regra de casamento de primos cruzados bilaterais. Este princípio implica necessariamente uma dicotomia básica entre parentes de ligação do mesmo sexo e do sexo oposto, que distingüe, respectivamente, posições como irmão do pai e irmão da mãe, irmã da mãe e irmã do pai, primo paralelo e primo cruzado, filhos do irmão (ego masculino) e filhos da irmã, etc., todas elas fundadas na variação desse parâmetro. Tal distinção corresponde ao eixo central desses sistemas, em torno do qual os parentes de um determinado indivíduo se distribuem em uma das duas categorias terminológicas mutuamente exclusivas, a dos paralelos (consangüíneos) e cruzados (afins). Assim, a distinção entre indivíduos do mesmo sexo e indivíduos do sexo oposto como parentes de ligação está na base dos processos de produção de identidades e diferenças sociais, a partir dos quais os indivíduos se definem uns em relação aos outros. Seria então de se esperar, tendo em vista 
o seu caráter central na esfera dos conceitos nativos, que pelo menos em algum de seus registros, os sistemas de atitude fossem igualmente infletidos por esse princípio. Este último ponto nos leva a um próximo passo, a saber, a aproximação das categorias de identidade e de diferença às de proximidade e distância social, respectivamente. Sabemos que tais correlações são recorrentes nas etnografias dos povos da região em diversos níveis.

A matriz apresentada por Rivière, retomada na Figura 6, ao definir dois graus de proximidade e distância social para a caracterização das quatro posições de parentesco da geração de ego (irmão, irmã, primo cruzado, prima cruzada) prevê um total de vinte quatro possibilidades combinatórias. ${ }^{3}$ Ao afirmar a inexistência de padrões de atitudes na Região, estaríamos tacitamente admitindo que tudo aí pode acontecer, isto é, que todas as possibilidades lógicas corresponderiam a possibilidades sociológicas.

Mas seriam mesmo, todas elas, sociologicamente pensáveis na região? Para que possamos explorar melhor esta questão, devemos elaborar um quadro, com base no sistema notacional proposto por Rivière, com todas as combinações possíveis dos valores ('++' ' + ' '-' '--' ), tendo como referência as quatro posições de parentesco da geração de ego. Por comodidade expositiva, na Figura 6 , sub-dividimos as vinte quatro possibilidades em seis sub-classes distintas (A,B,C,D,E,F).

Um retorno às etnografias nos permite constatar que alguns padrões atitudinais gerados pela matriz não encontram correspondentes na etnografia, como aqueles definidos pelas sub-classes (E) e (F). Esta ausência de exemplos etnográficos para determinadas combinações poderia, evidentemente, vir a ser tomada como acidental, fruto do acaso, tendo em vista o caráter inevitavelmente fragmentário e incompleto do corpus etnográfico. Esta não é, entretanto, a única maneira de tratar o fenômeno. Estamos diante de duas alternativas: uma delas é afirmar o acaso; outra é procurar uma razão capaz de explicar a não ocorrência, no corpus norte amazônico, de certas combinações atitudinais. ${ }^{4}$

3 As possibilidades combinatórias estão nesse caso limitadas ao fato de que nenhum dos valores $(++,+,-,--)$ se repete em um mesmo caso. Sem esta limitação, o número de combinações seria muito maior.

4 Tais alternativas não seriam, é claro, as únicas possíveis. Uma terceira via seria a de tentar demonstrar que a inexistência de padrões atitudinais na região talvez pudesse corresponder a um esforço dessas sociedades para ultrapassar ou resolver contradições expressas nas próprias terminologias, que é o que parece ocorrer em alguns casos mencionados por Lévi-Strauss (1945:54), como entre os Apache e os Yuma (América do Norte) e entre os Wik Munkan (Austrália). Nada nos autorizaria a sugerir, no entanto, uma solução do mesmo tipo para os exemplos sul-americanos em questão. Fiquemos, então, com as nossas duas alternativas apenas. 
PARENTESCO E ORGANIZAÇÃO SOCIAL NA AMAZÔNIA

FIGURA 6

AS POSSIBILIDADES COMBINATÓRIAS

\begin{tabular}{|c|c|c|c|c|}
\hline $\begin{array}{l}\text { parentes } \\
\text { povos }\end{array}$ & irmão & irmã & $\begin{array}{c}\text { primo } \\
\text { cruzado }\end{array}$ & $\begin{array}{c}\text { prima } \\
\text { cruzada }\end{array}$ \\
\hline $\begin{array}{l}\text { (A) } \\
\text { Pemom }\end{array}$ & $\begin{array}{c}++ \\
+ \\
++ \\
+\end{array}$ & $\begin{array}{c}+ \\
++ \\
+ \\
++\end{array}$ & $\begin{array}{l}- \\
- \\
-- \\
--\end{array}$ & $\begin{array}{l}-- \\
-- \\
- \\
-\end{array}$ \\
\hline $\begin{array}{l}\text { (B) } \\
\text { Piaroa } \\
\text { Trio }\end{array}$ & $\begin{array}{c}++ \\
+ \\
++ \\
+\end{array}$ & $\begin{array}{l}- \\
- \\
-- \\
--\end{array}$ & $\begin{array}{l}-- \\
-- \\
- \\
-\end{array}$ & $\begin{array}{c}+ \\
++ \\
+ \\
++\end{array}$ \\
\hline $\begin{array}{l}\text { (C) } \\
\text { Waimiri-Atroari } \\
\text { Panare }\end{array}$ & $\begin{array}{c}++ \\
+ \\
++ \\
+ \\
\end{array}$ & $\begin{array}{l}- \\
- \\
-- \\
-- \\
\end{array}$ & $\begin{array}{c}+ \\
++ \\
+ \\
++\end{array}$ & $\begin{array}{l}-- \\
-- \\
- \\
-\end{array}$ \\
\hline $\begin{array}{l}\text { (D) } \\
\text { Ye'cuana }\end{array}$ & $\begin{array}{l}- \\
-- \\
- \\
--\end{array}$ & $\begin{array}{l}-- \\
- \\
-- \\
-\end{array}$ & $\begin{array}{c}++ \\
++ \\
+ \\
+\end{array}$ & $\begin{array}{c}+ \\
+ \\
++ \\
++\end{array}$ \\
\hline (E) & $\begin{array}{l}- \\
-- \\
- \\
--\end{array}$ & $\begin{array}{c}++ \\
++ \\
+ \\
+\end{array}$ & $\begin{array}{l}-- \\
- \\
-- \\
- \\
\end{array}$ & $\begin{array}{c}+ \\
+ \\
++ \\
++\end{array}$ \\
\hline$(F)$ & $\begin{array}{l}- \\
-- \\
- \\
--\end{array}$ & $\begin{array}{c}+ \\
+ \\
++ \\
++\end{array}$ & $\begin{array}{c}++ \\
++ \\
+ \\
+\end{array}$ & $\begin{array}{l}-- \\
- \\
-- \\
-\end{array}$ \\
\hline
\end{tabular}


Se a afirmação do acaso sempre traduz uma atitude mais prudente, por outro lado, a renúncia de esforços para uma solução apenas dissolve o enigma inicial, a saber, o convívio de uma estrutura terminológica indiscutivelmente recorrente na Região, acompanhada da ausência absoluta de padrões de atitudes a ela relacionados. Entretanto, se não nos contentarmos com a evocação do acaso, devemos formular uma hipótese tentativa para o problema que, se vier a ser declarada falsa diante de novas informações etnográficas, poderá pelo menos reivindicar o mérito de ter servido de ponto de partida para a formulação de modelos mais precisos sobre os sistemas de atitudes na região. Isso posto, é hora de retomar a questão, procurando, antes de mais nada, afastar algumas hipóteses que, sabemos de antemão, não resistiriam às primeiras críticas.

Diríamos, para começar, que não podemos supor que, em todos os níveis, as relações entre os indivíduos de mesmo sexo sejam socialmente mais próximas ('+' ou ' ++') que as relações com o sexo oposto. Os casos piaroa e trio forneceriam evidências contrárias a esta afirmação. Da mesma forma, como Rivière sublinhou, não há uma relação direta entre as categorias de afinidade e de distância social. Os casos panare e waimiri-atroa$r i$ se insurgiriam contra esta hipótese. Além disso, o caso pemon nos alertaria contra a possibilidade de associarmos a idéia de matrimonialidade, que caracteriza a relação entre primos cruzados de sexo oposto, às categorias de familiaridade e intimidade ('+' ou ' ++ '). Finalmente, o caso ye'cuana rejeitaria uma equação direta entre a consangüinidade e as categorias de proximidade social.

Há, no entanto, uma outra maneira de enfrentar o problema, retomando em outra clave a dicotomia entre as relações de identidade e diferença sexual. Segundo o cálculo dravidiano, os filhos de um consangüíneo do mesmo sexo e mesma geração dos pais de ego, assim como os de seus afins de sexo oposto, são seus consangüineos. Inversamente, os filhos de consangüíneos de sexo oposto e de mesma geração dos pais deste indivíduo, assim como os de seus afins do mesmo sexo, são, em todos os casos, seus afins. Conseqüentemente, os filhos de um consangüíneo do mesmo sexo e mesma geração de um indivíduo, assim como os de seus afins de sexo oposto, são consangüineos dos filhos de ego. Enquanto isso, os filhos de consangüíneos de sexo oposto e mesma geração de um indivíduo, assim como os de seus afins do mesmo sexo, são seus afins.

Como procurei demonstrar em outro lugar, entre os Waimiri-Atroari, a "relação entre [consangüineos do mesmo sexo e mesma geração] consti- 
tui a expressão máxima da consangüinidade e, analogamente, a relação entre [afins do mesmo sexo e mesma geração], a expressão máxima da afinidade" (Silva 1995:55). A noção de "expressão máxima" traduz a idéia de que tais relações não apresentam qualquer grau de ambiguidade. Os filhos de irmãos e dos primos cruzados do mesmo sexo são, assim como seus pais, consangüíneos ou afins, respectivamente. Entre esses pontos extremos ("expressões máximas"), situam-se, por exemplo, os irmãos e os primos cruzados de sexo oposto, "expressões mínimas" da afinidade e da consangüinidade, respectivamente. Enquanto os primeiros, embora consangüíneos, geram afins na geração seguinte, os segundos, da mesma forma, correspondem a afins geradores de consangüíneos. Em suma, "a expressão mínima da consangüinidade equivale a um princípio de afinidade entre germanos e, inversamente, a expressão mínima de afinidade remete a um princípio de consangüinidade entre afins" (Silva 1995:55).

$\mathrm{O}$ caso pemon, revelador de atitudes de maior proximidade entre irmãos do que entre primos cruzados/cunhados, independente do sexo desses parentes, poderia ser interpretado como a afirmação, na geração dos pais de ego, do princípio elementar de identidade e diferença sexual . Por esta razão, os filhos de FB e MZ seriam socialmente mais próximos que os filhos de MB e FZ. Analogamente, poderíamos supor que os casos piaroa e trio estivessem afirmando, na geração dos filhos de ego, esse mesmo princípio, o que permite reunir o irmão e a prima cruzada, uma vez que ambos geram indivíduos classificados como idênticos (consangüíneos) aos filhos de ego. Finalmente, os casos panare, waimiri-atroari e ye'cuana permitiriam verificar, na geração de ego, a afirmação deste mesmo princípio, já que, em todos esses casos, o parente de mesmo sexo é sempre mais próximo que o seu correspondente de sexo oposto.

Ora, as possibilidades combinatórias (E) e (F) da Figura 6, por sua vez, não afirmam esta equação elementar (próximo:idêntico::distante:diferente) em qualquer um dos níveis geracionais considerados, de resto os únicos que serviriam de tela para a projeção de tal princípio, ${ }^{5}$ mas parecem, ao contrário, embaralhá-lo. Os demais casos (D), com exceção daquele representado pelos ye'cuana, em que os parentes de mesmo sexo da geração de

5 Na grade apresentada acima (Figura 1), a oposição consangüíneo/afim se manifesta terminologicamente apenas nas três gerações mediais $(0,+1$ e -1$)$, sendo neutralizada nas gerações distais (+2 e -2), o que corresponde à paisagem típica. Nos sistemas terminológicos que distinguem consangüíneos e afins nas gerações distais, encontraríamos novos ambientes para a manifestação deste princípio na esfera atitudinal, o que evidentemente implicaria em alterações do quadro de possibilidades sociológicas. 
ego são mais próximos que os seus equivalentes de sexo oposto, nublam, da mesma forma, a expressão deste princípio. A situação é diferente em relação às possibilidades (A), (B) e (C), para as quais não temos exemplos etnográficos reais mas que, se estivermos certos, seríamos obrigados a admitir que poderiam perfeitamente ocorrer. Em síntese, gostaríamos de supor que, ao contrário daquelas possibilidades combinatórias que negam a expressão do princípio de base, essas últimas seriam sociologicamente plausíveis na região, embora talvez não encontremos exemplos etnográficos para todas elas.

Uma vez que o princípio de base aqui postulado implica diretamente a troca direta, regime que atravessa toda a região, somos ainda levados a supor que a variabilidade do dado etnográfico, tanto no plano das terminologias quanto no plano das atitudes, encontre aí os seus limites. Afinal, não devemos esquecer que "a função de um sistema de parentesco é gerar possibilidades ou impossibilidades de matrimônios, quer diretamente entre pessoas que se tratam por certos termos, quer indiretamente entre as que se tratam por termos derivados, de acordo com regras determinadas, daqueles usados por seus ancestrais" (Lévi-Strauss [1965] 1969:127-8). Isso posto, formulamos a hipótese de que combinações como (E) e (F) são sociologicamente implausíveis na região, tanto quanto seria, por exemplo, a ocorrência de um vocabulário de outro tipo, como, por exemplo, os de tradição ocidental enquanto o "princípio de troca direta prescritiva" continuar a operar como fórmula organizadora das estruturas da aliança. A consideração do caso mamo (uma facção Karinya estudada por Schwerin) permitiria observar que a grade dravidiana parece resistir, mesmo nos contextos em que os termos do vocabulário indígena foram substituídos por equivalentes das línguas européias. Assim, por exemplo, em mamo, os vocábulos espanhóis "tio" e "tia", assim como "primo" e "prima" correspondem a posições de afinidade e não de consangüinidade (Schwerin 1984:138).

Pelas mesmas razões que não podemos determinar a priori o número a ser sorteado por um dado, não poderíamos igualmente pretender determinar em que registro um sistema de atitudes qualquer deve expressar o princípio da troca simétrica (direta). Mas graças à forma cúbica dos dados, sabemos que só há seis resultados possíveis (e não mais de seis) em cada jogada. Não deveríamos, portanto, confundir os dois tipos de ausência de exemplos etnográficos para as possibilidades atitudinais apresentadas na Figura 6, um por razões contingentes, outro por motivos estruturais. 
Nossa hipótese de trabalho se filia à vertente teórica da disciplina que rejeita a atomização culturalista, fundada no culto à singularidade, uma vez que não se contenta em reafirmar ad nauseam a variabilidade do dado fenomenológico, mas visa, ao contrário, submetê-lo à pesquisa de mecanismos a eles subjacentes, capazes de revelar suas constantes. Nossa hipótese rejeita igualmente o que Héritier (1996:36) condena como a "proclamação da universalidade da natureza humana, traduzida em grandes arquétipos em que todas as culturas e sociedades podem ser confundidas".

Afastando-se, por um lado, da atomização culturalista e, por outro, da substantivação dos universais, o exercício de Heritier 1981, que nos serviu de inspiração para este, demonstrando a impossibilidade sócio-lógica de ocorrência de um certo padrão terminológico logicamente possível, esquecido por Lowie 1928 e Murdock 1949 em suas macro-tipologias, ${ }^{6}$ revela como as trilhas abertas pela teoria da aliança continuam a ser ainda as mais promissoras diante dos desafios intelectuais que, há mais de um século, os sistemas de parentesco propõem à disciplina antropológica.

A contribuição de Héritier tem o inegável mérito de insistir na compreensão da variabilidade cultural a partir da consideração do que denomina "mecanismos invariantes... que ordenam [esta variabilidade] $e$ lhe conferem ... sentido". Dessa perspectiva, os objetos etnográficos não corresponderiam a singularidades históricas irredutíveis e incomparáveis umas com as outras, mas de fato "a associações contingentes de traços pertinentes" (Héritier 1996:36). Ora, tal afirmação vai precisamente no sentido do exercício aqui proposto, que procura explorar a intuição de que as variantes vocabulares e atitudinais "resultam de aspectos estruturais mais básicos que podem explicar, eles mesmos, suas semelhanças e diferenças" (LéviStrauss [1965] 1969:127). Ao afirmar a implausibilidade de determinadas configurações terminológicas e atitudinais no caso em questão, não estamos pressupondo um cenário teórico enfadonho em que terminologias e atitudes estejam sempre a nos dizer as mesmas coisas. A premissa da integração dinâmica entre as duas ordens não se confunde, como lembramos acima, com a de correspondência termo a termo entre vocabulário e atitudes.

A título de conclusão, convém assinalar que a reconsideração desses aspectos do parentesco amazônicos pretendida neste artigo permite ainda retomar uma teima, já enunciada em trabalhos anteriores (Silva 1993:322 e

6 Héritier se refere a um padrão terminológico caracterizado pela equação $\mathrm{F}=\mathrm{MB} \neq \mathrm{FZ}$ que, curiosamente não é de fato contemplado pelas "possibilidades lógicas" de Lowie 1928:266 como também pelos seis grandes tipos de Murdock 1949. 
Silva 1995:60, nt.38), que diz respeito diretamente a um aspecto, a meu ver, negligenciado do debate sobre a região: a de que não seria inútil continuar insistindo que o amorfismo e a fluidez, conceitos bastante acionados na caracterização da organização social dos povos amazônicos, deveriam ser tomados como efeitos de um determinado tipo de estrutura social e não como causas da variabilidade de situações lá encontradas.

\section{Glossário:}

Alter:

O termo Alter corresponde à pessoa que se classifica, ao parente designado.

Casamento Avuncular:

Casamento do irmão da mãe com a filha da irmã.

Casamento Bilateral:

Casamento de primos cruzados bilaterais.

Casamento virilocal:

Casamento caracterizado pela residência no grupo local do marido. Ego:

O termo Ego designa a posição a partir da qual se traçam as relações de parenteco.

Filiação indiferenciada:

Qualidade de membro de um grupo transmitida indiferentemente por via paterna ou materna.

\section{Germanos:}

Conjunto de irmãos e irmãs.

Irmão classicatório:

Parente classificado como irmão, filho de pai e mãe diferentes dos de ego. Nos sistemas amazônicos, a categoria inclui os primos paralelos, os filhos dos primos paralelos dos pais, etc..

Oposição concêntrica:

Oposição em que os termos se relacionam assimetricamente.

Oposição diametral:

Oposição em que os termos se relacionam simetricamente. 
Parente de ligação:

Parente(s) que liga(m) Ego a Alter.

Primos cruzados:

Filhos de germanos de sexo oposto.

- bilaterais:

Filhos de germanos de sexo oposto, ligados a ego por sua mãe e por seu pai.

- matrilaterais:

Filhos de germanos de sexo oposto, ligados a ego por sua mãe.

- patrilaterais:

Filhos de germanos de sexo oposto, ligados a ego por seu pai.

Primos paralelos:

Filhos de dois irmãos ou de duas irmãs.

Sistema de metades:

Sistema que divide globalmente uma sociedade, normalmente com base em um princípio de unifiliação, em dois grupos mutuamente exclusivos.

Sistema Terminológico:

Vocabulário de parentesco, Terminologia de parentesco.

Sistema (de Parentesco)

- Havaiano:

Vocabulário em que ego classifica com um único termo seus irmãos, seus primos paralelos e seus primos cruzados.

- Iroquês:

Vocabulário em que ego classifica com um único termo seus irmãos e seus primos paralelos, e com um outro termo os seus primos cruzados, não fazendo, contudo, a identificação desses últimos a seus afins.

- Dravidiano:

Vocabulário em que ego classifica com um único termo seus irmãos e seus primos paralelos, e com um outro termo os seus primos cruzados. Além disso, um vocabulário dravidiano torna terminologicamente idênticos o sogro e o tio materno, a sogra e a tia paterna, os primos cruzados os cunhados, os filhos de germano de sexo oposto e os genros e noras, etc.. Tais identificações são explicáveis com base na regra de casamento de primos cruzados bilateral. 
- Crow:

Vocabulário em que ego classifica com um único termo seus irmãos e seus primos paralelos. Os primos cruzados matrilaterais e patrilaterais são classificados com termos diferentes, os primeiros identificados aos filhos de ego, os segundos, a seu pai e tia paterna.

- Omaha:

Vocabulário em que ego classifica com um único termo seus irmãos e seus primos paralelos. Os primos cruzados matrilaterais e patrilaterais são classificados com termos diferentes, os primeiros identificados à mãe e ao irmão da mãe de ego, os segundos identificados a seus filhos.

Troca simétrica:

Intercâmbio matrimonial característico das estruturas de parentesco que operam com uma regra de casamento bilateral. Neste regime, os dois termos envolvidos na troca (grupos ou indivíduos) são ao mesmo tempo doadores e receptores, um em relação ao outro. Sin: Troca direta.

Uxorilocalidade:

Regra de residência que determina que o casal viva permanente ou temporariamente com os parentes da esposa. O contrário de Virilocalidade.

\section{Referências:}

ADAMS, K.J. The Barama River Caribs of Guyana restudied: forty years of cultural adaptation and population change. Ph.D. thesis. Case Western Reserve University.

Arvelo-Jimenes, N. Political relation in a tribal society: a study of the Ye'cuana Indians of Venezuela. Cornell University Latin American Program Dissertation Series 31, 1971.

DumONT, L.. Le vocabulaire de parenté dravidien comme expression du mariage. In: Dravidien et Kariera: l'alliance de marriage dans l'Inde du Sud et en Australie. Paris. Mouton, [1953] 1975.

- Heérarchie et alliance de mariage dans la parenté de l'Inde du Sud. In: Dravidien et Kariera: l'alliance de marriage dans l'Inde du Sud et en Australie. Paris. Mouton, [1957] 1975.

- Introduction à deux theories d'anthropologie sociale. Paris, Mouton, 1971. 
Durkheim, E. La prohibition de l'inceste et ses origines. Anneé Sociologique, I: 1-70, 1897

Henley, P. The Panare. Tradition and change on the Amazonian frontier. New Haven, Yale University Press, 1982.

- South Indian Models in the Amazonian Lowlands. Manchester Papers in Social Anthropology, n. ${ }^{\circ}$ 1, 1996.

Héritier, F. L'exercice de la Parenté. Paris, Gallimard/Le Seuil, 1981.

- Parentesco. Enciclopédia Einaudi. Lisboa: Imprensa Nacional - Casa da Moeda, 1989.

- Masculin / Féminin: la pensée de la différence. Paris, Editions Odile Jacob, 1996.

Hornborg, A. Dualism and Hierarchy in Lowland South America: Trajectories of Indigenos Social Organization. Uppsala Studies in Cultural Anthropology, 9. Estocolmo: Almqvist \& Wiksell, 1988.

KoEHN, S.S. Apalaí kinship and social behavior. Arquivos de Anatomia e Antropologia 1, 1975, pp. 79-108.

KroEber, A. L. "Classicatory Systems of Relationship". Journal of Royal Anthropological Institute, 39, pp. 77-84, 1909.

KUPER, A. The Invention of Primitive Society: Transformations of an Illusion. London: Routledge, 1988.

LAPOINTE, J. Residence pattern and Wayana social organization. Ph.D. thesis. Columbia Unversity.

LaraiA, R. de B.. "Os estudos de parentesco no Brasil". Boletim de Informações Bibliográficas /ANPOCS n. ${ }^{\circ}$ 23, 1987, pp.3-17.

LÉVI-Strauss, C. "The social use of kinship terms among Brazilian Indians". American Anthropology, 45, 1943, pp.398-409.

- A análise estrutural em lingüística e em antropologia". Antropologia Estrutural, Rio de Janeiro, Tempo Brasileiro, [1945]1975.

- La vie familiale et sociale des indiens Nambikwara, Paris. Société des Americanistes, 1948.

- Les structures élémentaires de la parenté. Paris: Mouton, [1949] 1967.

- "Lingüística e Antropologia". Antropologia Estrutural, Rio de Janeiro, Tempo Brasileiro, [1952]1975.

- "O Futuro dos Estudos de Parentesco". In: Laraia, R.B. (org.) Organização Social. Rio de Janeiro, Zahar, [1965]1969.

LounsburY, F. "A Formal Account of the Crow and Omaha-Type Kinship Terminologies". In: Goodenough, W., ed. Explorations in Cultural Anthropology. Nova Iorque, McGraw-Hill, pp. 351-394, 1964. 
LowIE, R. H. "A note on relationship terminologies". American Anthropologist 30, 1928, pp 263-267.

— "Relationship Terms". [s.d.] in Bohannan, P. \& Middleton, J. Kinship and Social Organization. The Natural History Press, 1968.

MaIne, H. S. Ancient Law, 1861 (ed. rev. Oxford Univ. Press, 1931).

MalinowsKi, B. "Kinship". Man 30:2, 1930, pp 19-29.

Mauss, M. Essai sur le don: forme et raison de l'échange dans les sociétés archaïques. In: Sociologie et Anthropologie. Presses Universitaires de France, [1923-4] 1950.

Mclennan, J.F. Studies in ancient history. Londres, Macmillan, 1876.

Morgan, L. Systems of consanguinity and affinity of the human family. Washington, Smithsonian Institution, 1870.

MuRDOCK, G.P. Social Structure. Nova Iorque, Macmillan, 1949.

NeEDHAM, R. Rethinking Kinship and Marriage. Londres: Tavistock. ASA Monographs II), 1971.

Nimuendauu, C. The Apinayé. Washington. Catholic University of American Press, 1939.

- The Serente. Los Angeles. Frederick Weeb Hodge Aniversary Publication, 1942.

- The Eastern Timbira. Berkeley. University of California Press.

Overing J. The Piaroa. A people of the Orinoco Basin. Oxford, Clarendon Press, 1975.

- Dualism as an Expression of Difference and Danger: Marriage Exchange and Reciprocity Among the Piaroa od Venezuela. In: Kensinger, K. (Org.) Marriage Practices in Lowland South American Societies. University of Illinois Press, 1984, pp. 127-155.

RADCLIFFE-Brown, A.R. "The study of kinship systems". in Structure and Function in Primitive Society. Routledge, Kegan Paul. [1940]1952.

- "Introduction". In: Radcliffe-Brown, A.R. e Forde, D. (orgs.) African Systems of Kinship and Marriage, 1950.

RIVERS, W.H.R. "Terminologia classificatória e matrimônio com primo cruzado". In Oliveira, R.C. de, Org. A Antropologia de Rivers. Campinas, Edunicamp [1913] 1991.

RiviÈre, P. Marriage among the Trio. Oxford, Clarendon Press, 1969.

- Individual and Society in Guiana: A comparative study of Amerindian social organization. Cambridge, Cambridge University Press, 1984.

Scheffler, H. "Dravidian-Iroquois: The Melanesian Evidence". In: Hiatt, L.R., Jayawardena, C. (orgs.). Anthropology in Oceania, Essays 
Presented to Ian Hogbin. Sidney, Angus and Robertson, 1971. pp 231-254.

SCHNEIDER, D. "What is kinship is all about?". In: Reining, P. (Org.), Kinship studies in the Morgan Centennial Year. Washington: Anthropological Society of Washington, pp. 32-63.

SCHWERIN, K. "The kin-integration system among Caribs". Antropologica, 59-62, 1984. pp 125-153

SILVA, M.F "O parentesco waimiri-atroari: algumas observações preliminares".In Viveiros De Castro, E. \& Carneiro Da Cunha, M. (orgs.) Amazônia: Etnologia e História Indígena. São Paulo, NHII/USP/FAPESP, 1993a.

- Romance de Primas e Primos: uma etnografia do parentesco waimiri-atroari. Tese de Doutorado. Museu Nacional, Universidade Federal do Rio de Janeiro, 1993b.

- "Sistemas dravidianos na Amazônia: o caso waimiri-atroari". In Viveiros De Castro, E. (Org.) Antropologia do Parentesco: estudos ameríndios. Rio de Janeiro, Editora da UFRJ, 1995.

Thomas, D.J. "Pemon zero generation terminology: social correlates". Working papers on South American Indians, 1, Social correlates of kin terminologies. Bennington College, 1978.

Trautmann, T. Dravidian Kinship. Cambridge, Cambridge University Press, 1981.

Viveiros DE CASTRO, E. "Alguns aspectos da afinidade no dravidianato amazônico". In Viveiros De Castro, E. \& Carneiro Da Cunha, M. (orgs.) Amazônia: Etnologia e História Indígena. São Paulo, NHII/USP/FAPESP, 1993.

- Pensando o Parentesco Ameríndio. In: Viveiros de Castro, E. (Org.) Antropologia do Parentesco: estudos ameríndios. Rio de Janeiro, Editora da UFRJ, 1995.

- O Problema da Afinidade na Amazônia. In: Viveiros de Castro, E. A Inconstância da Alma Selvagem. Ed. Cosac \& Naify, 2001.

YaLman, N. The Structure of the Sinhalese Kindred: A Re-Examination of the Dravidian Terminology. American Anthropology, v.64, n.3-1, 1962, pp. 548-575.

- Under the Bo Tree. Berkeley. University of California Press, 1967. 